\title{
Using Software to Solve Engineering Economy Problems
}

\author{
Mohammad Moshref-Javadi and Behzad Bankian Tabrizi
}

\begin{abstract}
In Engineering Economy like other engineering sciences, software is widely used for analyzing and dealing with various problems/projects. These applications could be for the purpose of, for example calculating the unknown parameters of the problem, beneficial analyses of projects, sensitivity analysis of the parameters of a given problem/project and other engineering and economic analyses .In this paper, the applications of different software programs in engineering economy for analyzing and solving various problems/projects are presented and each case is well explained by a practical example. This paper could be helpful both for teaching engineering economy at universities and also tackling real-world problems by practitioners.
\end{abstract}

Index Terms-Engineering economy, education, simulation, software applications.

\section{INTRODUCTION}

Today, software plays an important role in problem solving and decision making. There are rare cases in which manual computations can do the job. Due to complexity and large scale of today's problems and with regard to rapid advancements in computer technology, application of software in all disciplines of engineering is indeed inevitable. In addition, introduction of user-friendly software with easy-to-use graphical user interfaces has dramatically reduced the burden of complicated and time consuming computations. Engineering Economy is not excluded from these applications and computer software is widely used in this area.

Several papers have been published for better teaching of the Engineering Economy course [1]-[9]. In most of these papers, using software has been suggested as an appropriate way for teaching this course. Therefore, how to use software and apply it in engineering economy is essential both for analyzing and solving practical problems/projects and teaching this course at universities.

The main concern in engineering economy is to select the most beneficial alternative among a set of given alternatives, with regard to some considerations such as time value of money and limited resources. Common questions particularly of economic aspects in this field are divided into two categories: 1- calculation of the interest rate, cash flow and other parameters of the problem and, 2- selecting the best alternative among various alternatives with different features [2]. Thus, software could be used for such purposes as recognizing and selecting the best alternative among others, beneficial analysis of the project, calculation of unknown

Manuscript received August 4, 2013; revised October 23, 2013.

The authors are with the Iran University of Science and Technology, Iran (e-mail: mohammad_moshref_j@ind.iust.ac.ir). parameters like rate of return of a given project, etc. Moreover, these applications could be accomplished in certain or uncertain environments.

Meyer [10] explained some of the software applications in engineering economy and explained EET software and the user interface in order to solve some problems in engineering economy. Ting et al. [11] applied BASIC to analyze the beneficial aspect of a project in a greenhouse. Bafna and Aller [12] recommended software using and especially spreadsheets for teaching engineering economy at universities. Alloway [13] illustrated the use of spreadsheets in engineering economy by an example. Spreadsheets have been under consideration by more authors [4], [14]-[18]. Also, Seila and Banks [19] showed how to use Lotus123 in order to solve a problem in engineering economy by simulation. Coates and Kuhl [20] illustrated the use of simulation software for solving engineering economy problems by three examples. The authors involved various types of uncertainty in the problems and applied the Monte Carlo method in order to reduce the risks in this uncertain environment whereas SLAMII was used.

This considerable literature shows that the uses of suitable software to solve various problems in engineering economy have a great deal of importance. In this paper, these applications are shown by appropriate software and each application is well-explained by a practical example. These applications include those of programming languages, simulation software in economic-financial dynamic systems, spreadsheets in engineering economy and finally special software and packages.

\section{APPLICATIONS OF PROGRAMMING LANGUAGES}

Banks [21] defines simulation as the imitation of the operation of a real-world process or system over time. Simulation is the process of modeling a system or operation and experimenting with this model under various scenarios in order that we can analyze the behavior of the system and select the best scenario. Finally, the best results (scenarios) could be selected. Maybe the most famous simulation method is the Monte Carlo method. Due to simplicity and intelligibility, this method is widely used in dealing with problems. In this method, the probability distributions of the uncertain parameters of the problem and random numbers are needed. In engineering economy many parameters might show uncertain behavior, such as rate of return, initial cost, annual benefit or cost and etc. The main reason for using simulation in engineering economy is the existence of uncertain parameters in the problem that Monte Carlo is a reliable method to deal with this uncertainty. The use of programming software in engineering economy is shown in this section by a sample problem and in uncertain environment. 
Problem 1: NPV estimation in uncertain environment. Suppose a project in which benefits, costs, project life and interest rate are uncertain. Benefit follows Normal distribution and the distribution parameters vary year by year given in Table I. Costs are uniformly distributed between $\$ 300$ and $\$ 500$. Project life is 4 years with a probability of 0.3 , 5 years with a probability of 0.4 and 6 years with a probability of 0.3 and finally interest rate (i) varies annually which has the distribution of $\mathrm{N} \sim(14 \%, 1 \%)$. The aim is to determine whether the project is profitable or not.

TABLE I: VALUES OF AVERAGE AND STANDARD DEVIATION FOR THE NORMAL DISTRIBUTION OF BENEFIT IN EACH YEAR

\begin{tabular}{ccc}
\hline \hline Year $(\mathbf{j})$ & $\mathbf{E}\left(\mathbf{B}_{\mathbf{i}}\right)$ & $\mathbf{S D}\left(\mathbf{B}_{\mathbf{j}}\right)$ \\
\hline 1 & 340 & 10 \\
2 & 460 & 10 \\
3 & 350 & 21 \\
4 & 430 & 13 \\
5 & 580 & 15 \\
6 & 510 & 10 \\
\hline \hline
\end{tabular}

Simulation model of the problem is given in Fig. 1. By repeating this process as many as the sampled project life and considering the yearly interest rate, NPV will be obtained, i.e.:

$$
N P V=\sum_{j=1}^{\text {project life }} \frac{N C F_{j}}{\left(1+i_{j}\right)^{j}}=\sum_{j=1}^{\text {project life }} \frac{\left(B_{j}-C_{j}\right)}{\left(1+i_{j}\right)^{j}}
$$

By performing the same process for 10000 iterations, we are able to depict the histogram of NPV. The more the number of iterations, the smoother the histogram will be obtained.

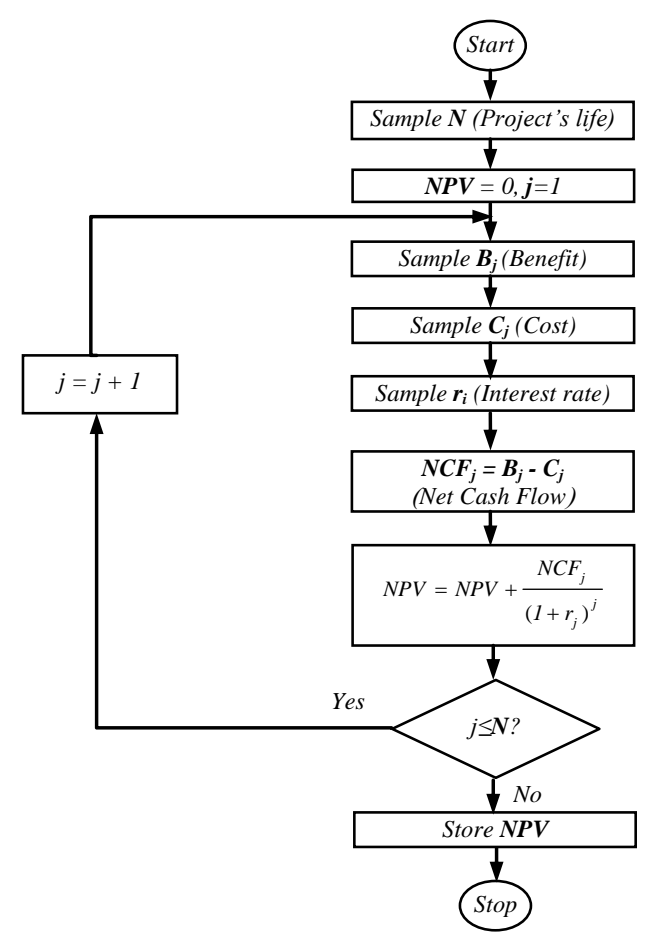

Fig. 1. NPV generation model with variable project life, benefit, cost and interest rate.

Performing the above stages 10000 iterations result in the NPV histogram. The histogram and the cumulative frequency diagram are shown in Fig. 2.
In accordance with NPV Normal distribution which is also proved by fitness test, thus:

$$
P(X>0)=P\left(\frac{X-55.79}{106.28}>\frac{0-55.79}{106.28}\right)=P(Z>-0.525) \approx 0.7
$$

Therefore this project is beneficial with the probability of 0.7 which is really a risky project. However, selecting such these projects depends on decision makers' utility function and more factors. This example is a simple illustration of programming language applications to solve engineering economy problems and could be more complicated when tax, inflation and more parameters and assumptions are involved in the problem.

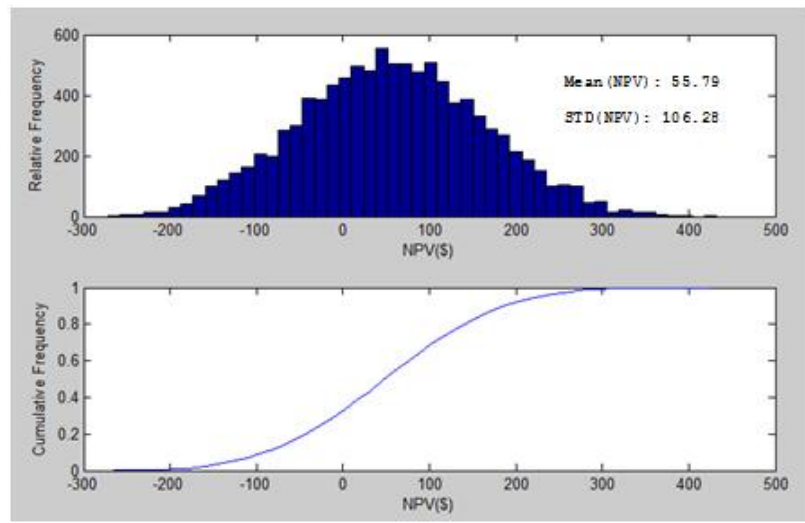

Fig 2. NPV histogram and cumulative frequency diagram after 10000 iterations.

\section{Simulation SOFTWARE In ECONOMIC-FinANCIAL DYNAMIC SYSTEMS}

Dynamic system (DS) aspect was first presented by Professor Jay Forrester at MIT in 1950 and Richard Bennett developed the first dynamic system modeling language in order to analyze these systems more specifically. Simulation is one way to deal with this problem and analyze them more accurately as we expect. The purpose here is to study economic-financial dynamic systems. Note that this type of software usages in engineering economy is limited in comparison to other applications. This kind of application is explained by an example here.

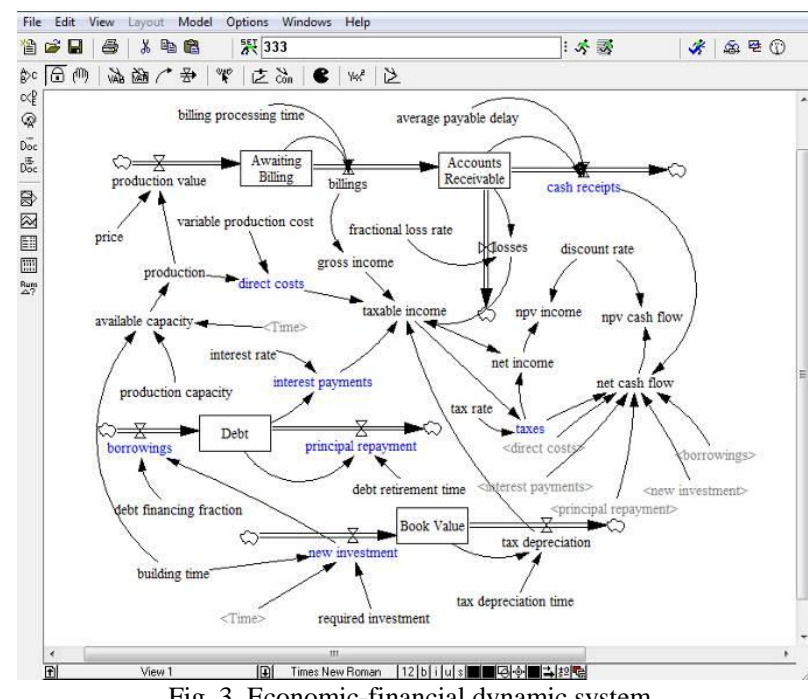

Fig. 3. Economic-financial dynamic system. 
Problem 2: The model shown in Fig. 3 demonstrates an economic-financial dynamic system which is taken from Vensim user's guide [22]. Considering the investment, production and tax, the purpose is to obtain the diagram of cash flow and net present value during the time. This model has been simulated for 10 years.

Results of the simulation are shown in Fig. 4 and Fig. 5. Fig. 4 shows net income curve with net cash flow in which the sudden change is caused by system equations whereas billings equate production value. Fig. 5 shows NPV of income and cash flow. These diagrams show the profitability of the system as a whole.

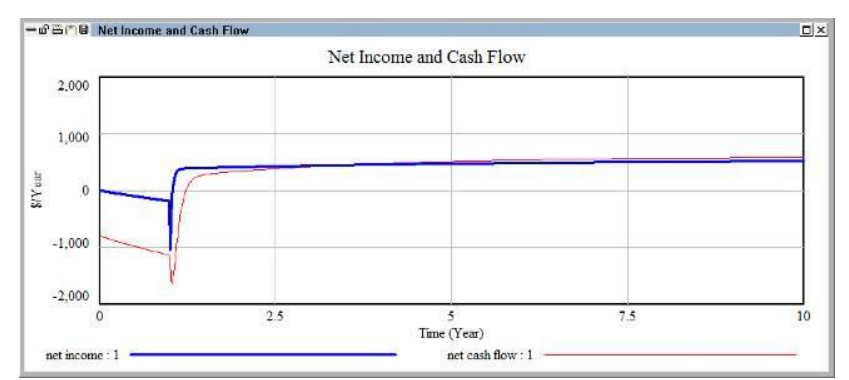

Fig. 4. Simulation results: net cash flow and net income.

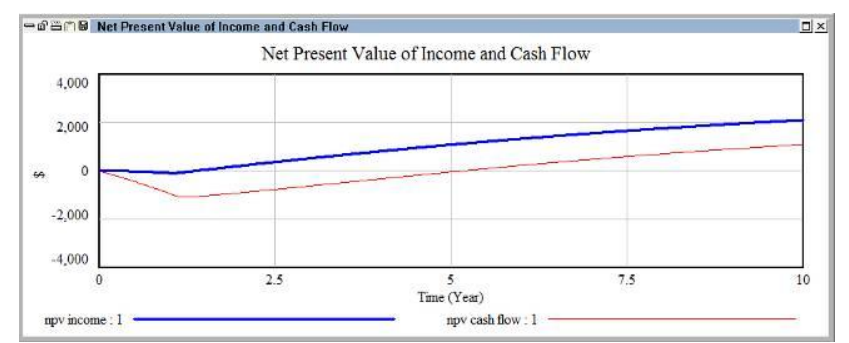

Fig. 5. Simulation results: NPV of cash flow and NPV of income.

\section{SPREADSHEETS IN ENGINEERING ECONOMY}

Spreadsheets are made up of small cells. In each cell, the data whether text, number or formula is inserted. Electronic spreadsheets have made the job easier. The most substantial advantage of spreadsheets is simplicity and intangibility working with them. In addition, spreadsheets are mostly economical.

As we noticed in the studied literature, spreadsheet applications are widespread and are noticeably used in economic and financial analyses. Most of the spreadsheets are capable of diagramming various charts, special function and different data analysis.

Some applications of spreadsheets in engineering economy and financial engineering are as follows:

- Portfolio optimization and selection

- Comparison of alternatives and choosing the best

- Cash flow generation and NPV/NFW calculation

- Calculating unknown parameters, e.g. rate of return

- Break-even analysis

- Equipment selection or replacement

- Resource allocation

- Loan analyzing

- Various types of beneficial analyses, e.g. benefit-cost analysis

- After tax analysis

Some of these files are ready to use, but one of the most practical advantages of spreadsheets is that the user can easily create a template file based on his/her needs and use it for solving different but similar problems.

Problem 3: Retirement point calculation. Suppose a $\$ 500,000$ investment must be made in year 2010 and $\$ 8480$ is withdrawn each year (j) for personal expenditure. This withdrawal is annually multiplied by $6 \%$ inflation rate(r). But the remained money at the end of each year benefits by $7 \%$ interest rate (i). The investor is interested to know how many years he will have money and when would be the best year to withdraw all of the invested money.

$$
\text { Withdraw }_{j}=\text { Withdraw }_{(j-1)} \times r
$$

$$
\begin{aligned}
& {\text { Remained } \text { money }_{j}=\text { Total }_{\text {money }}{ }_{j-1}-\text { Withdraw }_{j}} \\
& \text { Benefit }_{j}=\text { Remained }_{\text {mone }} \times{ }_{j}
\end{aligned}
$$

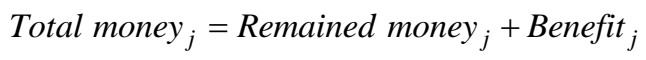

Microsoft Excel has been used to solve this problem and sample computations are shown in Fig. 6.

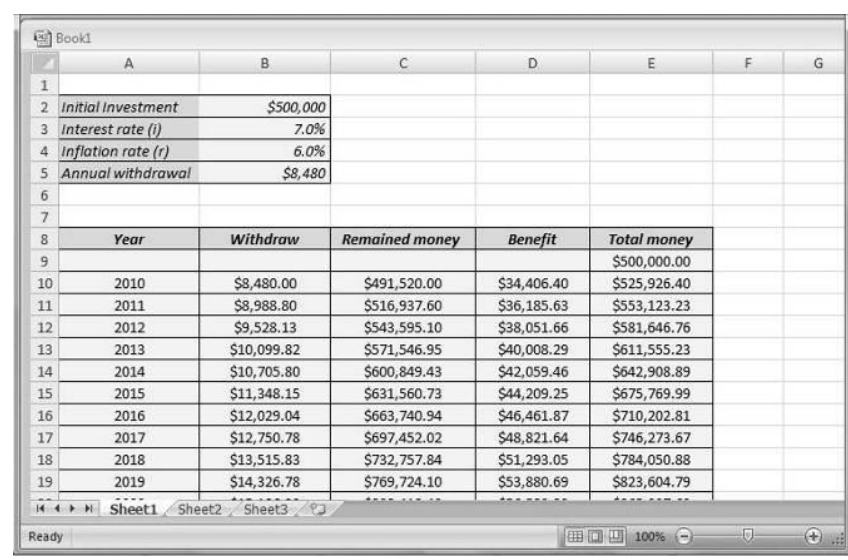

Fig. 6. Sample computations for retirement point in Microsoft Excel.

Fig. 7 shows that the money is accumulating up to year 2078 where it starts declining and finally in year 2094 no money remains.

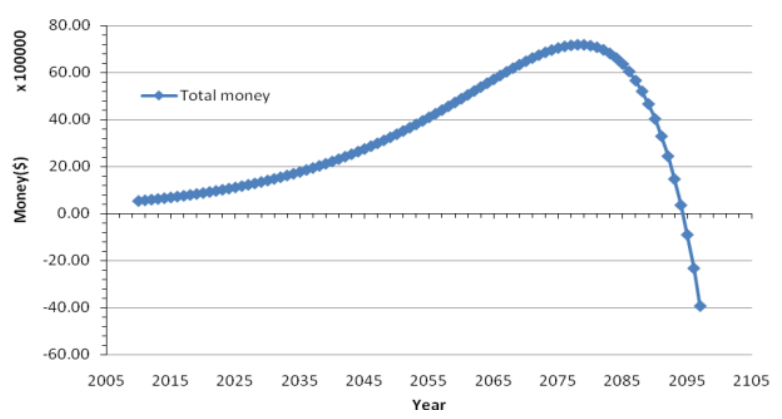

Fig. 7. Diagram of Total money according to given parameters values.

The sensitivity analyses of the parameters are presented in Fig. 8. Obviously interest rate and initial investment has positive impact on total money while inflation rate and annual withdrawal have negative impact. These diagrams show that interest rate and yearly withdrawal are more sensitive than other factors and should be noticeably considered than inflation rate and initial investment. Also this figure shows the importance of annual withdrawal especially 
for values less than $\$ 8000$. This simulation can be more actual and maybe complicated when the parameters of the problem are uncertain.
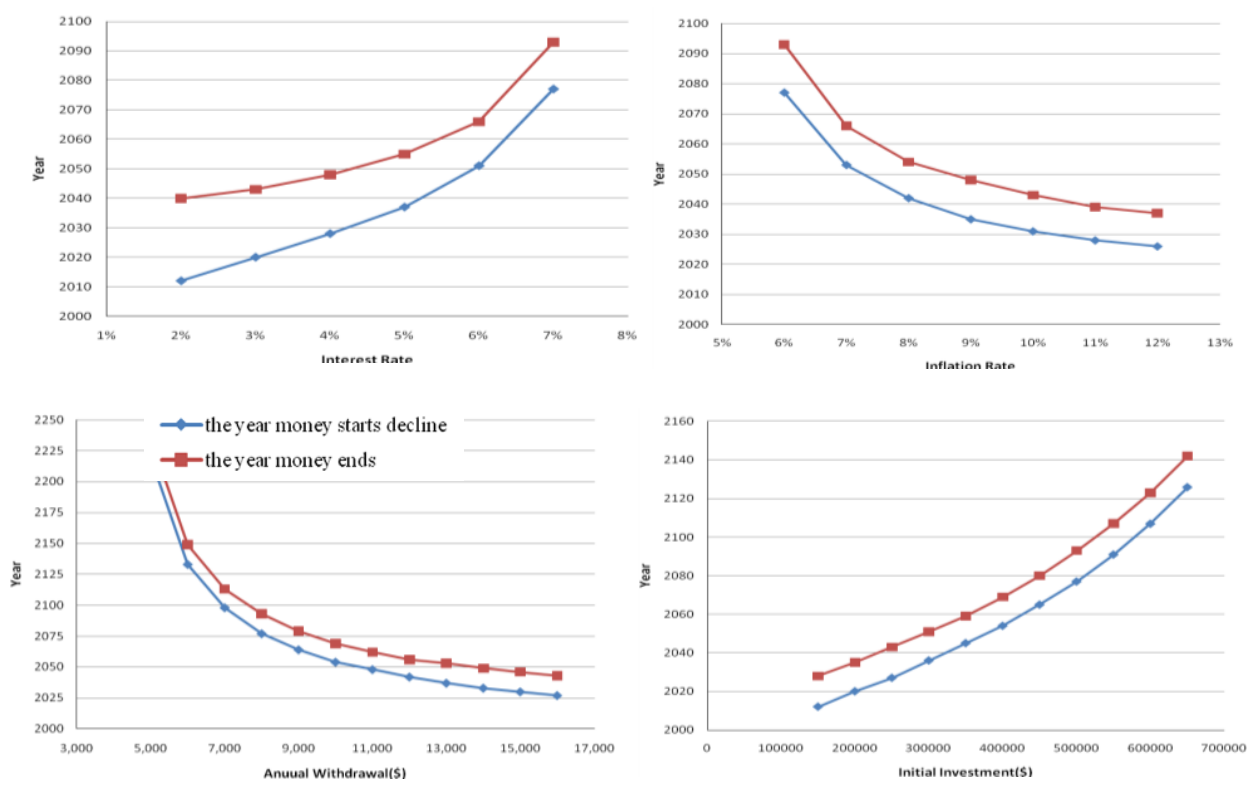

Fig. 8. Sensitivity analysis of interest rate, annual withdrawal, inflation rate and initial investment.

\section{SPecial SofTWARE AND PACKAGES}

This class of software in engineering economy consists of several software and packages which are usually used for special problems and decision makings. Some of these software and packages such as Camfar and BP-pro has particular options and capabilities which do not exist in any other classes of software that were presented in this paper. This class of software is usually applied for choosing the best alternative or feasibility study of projects. Graphic user interface, various types of charts, several beneficial analyses for example benefit-cost, performing sensitivity analysis while considering inflation, depreciation tax are available in this class of software.

Although some applications of software in engineering economy were presented in this paper, however, these applications are wider than it could all be studied here. This is obvious that these applications have some overlaps in some cases. The user should select the most effective and economical software based on the essence of the problem, advantages and price of software and user's capabilities and knowledge.

\section{CONCLUSIONS}

In this paper, the applications of software in engineering economy were studied and each application was shown by an example. Programming languages are usually used for simulating projects particularly in which there exist uncertain parameters. Software usage in analyzing economic-financial dynamic systems is rather limited in comparison to other software and programs. Spreadsheets are widely used in solving engineering economy problems. In fact, most of the economic and financial analyses could be performed by spreadsheets. Spreadsheets have substantial advantages specially simplicity and intangibility that convince the users to employ them to deal with different problems. As we noticed, most of software applications were in the fields of project simulation and especially in uncertain environment. In spite of the fact that the number of special software and packages for engineering economy have considerably increased during last decades, but still spreadsheets indeed play an important role in solving and analyzing engineering economy problems/projects.

\section{REFERENCES}

[1] J. Banks, J. S. Carson, and B. L. Nelson, Discrete-event system simulation, 2nd ed., New Jersey: Prentice Hall, 1996.

[2] K. D. Dahm, R. P. Ramachandran, and D. L. Silverstein, "Teaching engineering economy principles using a web-based, interactive simulation," in Proc. the 2004 American Society for Engineering Education Annual Conference \& Exposition.

[3] D. W. Elizandro and M. O. Matson, "Taking a moment to teach engineering economy," The Engineering Economist, vol. 52, pp. 97-116, 2007.

[4] T. Eschenbach and R. White, "Using spreadsheets to teach engineering economy," in Proc. Annual Conference Proceedings, American Society for Engineering Education, June 1992.

[5] A. K. Goyal, J. M. Tien, and P. A. Voss, "Integrating uncertainty considerations in learning engineering economy," The Engineering Economist, vol. 42, pp. 249-257, 1997.

[6] J. C. Hartman, "Suggestions for teaching engineering economy at the undergraduate level," The Engineering Economist, vol. 44, pp. $110-128,1999$.

[7] M. Mc.Bride and W. Winchester, "Teaching engineering economy: There has to be a better way," in Proc. the 31st International Conference on Computers and Industrial Engineering, San Francisco, California, February 2003, pp. 703-707.

[8] J. P. Lavelle, "Spreadsheet Applications in Engineering Economics (Book review)," The Engineering Economist, vol. 38, pp. 155-157, 1993.

[9] P. M. Lee and W.G. Sullivan, "Using Multimedia in an engineering economy course," ASEE Annual Conference Proceedings, 1996.

[10] B. C. Meyer, "A Graphics Interface to an Engineering Economy Program," Computers \& Industrial Engineering, vol. 13, pp. 351-355, 1987.

[11] K. C. Ting, J. Dijkstra, W. Fang, and M. Giniger, "Engineering economy of controlled environment for greenhouse production," Transactions of the ASAE, vol. 32, pp. 1018-1022, 1989.

[12] K. Bafna and B. Aller, "Enhancing the learning of engineering economy with innovative technology and teaching," American Society for Engineering Education, 2007. 
[13] J. A. Jr. Alloway, "Spreadsheets: Enhancing Learning and Application of Engineering Economy Techniques," The Engineering Economist, vol. 39, pp. 263-274, 1994.

[14] T. Eschenbach, H. Wiebe, and H. Yazici, "Spreadsheets vs. formulas for engineering economy instruction," Annual Conference Proceedings, American Society for Engineering Education, June 1991, pp. 530-534.

[15] T. Eschenbach, "Using spreadsheet functions to compute arithmetic gradients," The Engineering Economist, vol. 39, pp. 275-280, 1994.

[16] J. M. Fraser, "Introduction to Engineering Economy (Book review)," The Engineering Economist, vol. 39, pp. 369-372, 1994.

[17] J. P. Lavelle, "Engineering economy: A survey of current teaching practices," ASEE Annual Conference Proceedings, 1996.

[18] J. P. Lavelle, "Enhancing engineering economy concepts with computer spreadsheets," The Engineering Economist, vol. 41, pp. 381-386, 1996

[19] A. F. Seila and J. Banks, "Spreadsheet risk analysis using simulation," Simulation, vol. 57, pp. 163-170, 1990.

[20] E. R. Coates and M. E. Kuhl, "Using simulation software to solve engineering economy problems," Computers \& Industrial Engineering, vol. 45, pp. 285-294, 2003.

[21] J. Banks, Handbook of simulation, Georgia Institute of Technology, Georgia: John Wiley \& Sons, Inc, 1998.

[22] Vensim user's guide version 5.9. (2007). Ventana Systems Inc.. [Online]. Available: www.vensim.com/documentation.html.

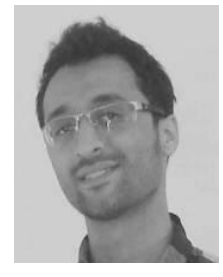

Mohammad Moshref-Javadi received his bachelor's in industrial engineering from Isfahan University of Technology, Iran, and his master's degree in industrial engineering from Iran University of Science and Technology, Iran. He is currently a PhD student in industrial engineering at Purdue University, USA. He has worked in the area of production systems, systems engineering, network design, and solution algorithms. Mr. Moshref-Javadi has got Institute of Industrial Engineers Lean paper competitions and NSF student awards.

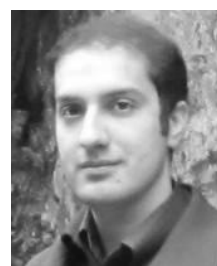

Behzad Bankian Tabrizi is a PhD student in industrial engineering at Iran University of Science and Technology. He got his bachelor's and master's degree in industiral engineering from Sadjad University, Iran and Iran University of Scinece and Technology respectively. His major areas of research are manufacturing systems design, facility location, and solution algorithms. Mr. Bankian has published papers in journals such as Applied Mathematical Modelling. 